\title{
Controle pelo Glyphosate e Caracterização Geral da SUPERFÍCIE FOLIAR DE Commelina benghalensis, Ipomoea hederifolia, Richardia brasiliensis E Galinsoga parviflora ${ }^{1}$
}

\author{
Control with Glyphosate and General Leaf Surface Characterization of Commelina \\ benghalensis, Ipomoea hederifolia, Richardia brasiliensis and Galinsoga parviflora
}

\author{
MONQUERO, P.A. ${ }^{2}$, CURY, J.C. ${ }^{3}$ e CHRISTOFFOLETI, P.J. ${ }^{4}$
}

\begin{abstract}
RESUMO - Este trabalho teve como objetivos caracterizar a superficie foliar das plantas daninhas Commelina benghalensis, Ipomoea hederifolia, Richardia brasiliensis e Galinsoga parviflora e determinar a porcentagem de controle dessas plantas pelo herbicida glyphosate. As ceras epicuticulares das plantas daninhas foram extraídas com clorofórmio e quantificadas $\left(\mu \mathrm{g} \mathrm{cm}^{-2}\right)$. Partes centrais das folhas foram submetidas à microscopia eletrônica de varredura, para caracterização da superfície foliar. A fim de avaliar a suscetibilidade dessas plantas daninhas ao glyphosate, foi instalado experimento inteiramente casualizado composto por sete tratamentos $(0,360,540,720,900,1.440$ e $2.160 \mathrm{~g}$ e.a. ha-1 de glyphosate) e quatro repetições em casa de vegetação, na Universidade de São Paulo, ESALQ/USP, Piracicaba-SP, Brasil. A eficácia do herbicida foi avaliada aos 14, 21 e 28 dias após aplicação dos tratamentos. As plantas daninhas não diferiram muito com relação à quantidade de ceras epicuticulares. Em G. parviflora a superficie foliar apresenta tricomas tectores multicelulares e estômatos anomocíticos. I. hederifolia apresenta superficie foliar rugosa, tricomas tectores unicelulares e glandulares e estômatos paracíticos. Em C. benghalensis, a superficie foliar apresenta dois tipos de tricomas tectores, estômatos tetracíticos e ceras dispersas na superficie adaxial. A planta daninha $R$. brasiliensis apresenta estômatos paracíticos e tricomas unicelulares. As plantas daninhas $C$. benghalensis e $R$. brasiliensis são mais tolerantes ao glyphosate do que as outras espécies estudadas. Com base nos dados obtidos, pode-se concluir que as plantas daninhas apresentam características foliares diferentes, sendo $C$. benghalensis e $R$. brasiliensis as mais tolerantes ao glyphosate, mesmo quando se utiliza a maior dose herbicida.
\end{abstract}

Palavras-chave: tolerância, anatomia foliar, ceras epicuticulares, absorção.

\begin{abstract}
This work aimed to characterize the foliar surface of the weeds Commelina benghalensis, Ipomoea hederifolia, Richardia brasiliensis and Galinsoga parviflora and the percentage of control by the herbicide glyphosate. The epicuticular waxes were extracted by chloroform and quantified $\left(\mu \mathrm{g} \mathrm{cm}^{-2}\right)$. Central parts of the leaves of these weeds were submitted to electron microscopy to characterize the foliar surface. To evaluate the susceptibility of these weeds to glyphosate an experiment was arranged in a randomized complete design, 7 treatments $\left(0,360,540,720,900,1440\right.$ and 2160 g a.e. ha ${ }^{-1}$ of glyphosate) and four replications under greenhouse conditions at the University of São Paulo - ESALQ/ USP - Piracicaba-SP, Brazil. Herbicide efficacy was assessed at 14, 21 and 28 days after treatment. In G. parviflora the foliar surface presents multicellular trichomes, and anomocytic stomata. In I. Hederifolia, the foliar surface is rough, with multicellular and glandular trichomes and paracytic stomata. In C. benghalensis, the foliar surface presents two types of trichomes and a lower number of tetracytic stomata. The presence of disperse wax was
\end{abstract}

Recebido para publicação em 12.2.204 e na forma revisada em 21.4.2005.

2 Doutora em Agronomia, área de concentração Fitotecnia, Departamento de Produção Vegetal, Universidade de São Paulo, Escola Superior de Agricultura "Luiz de Queiroz" - ESALQ/USP, Caixa Postal 09, 13418-900 Piracicaba-SP, Brasil, <pamonque@cca.ufscar.br>. ${ }^{3}$ Doutorando em Agronomia do Dep. de Microbiologia do Solo, ESALQ/USP; ${ }^{4}$ Professor Associado do Dep. de Produção Vegetal, ESALQ/USP. 
observed on the adaxial surface. $\boldsymbol{R}$. brasiliensis presents great number of unicellular trichomes and paracytic stomata. The weeds $\boldsymbol{C}$. benghalensis and $\boldsymbol{R}$. brasiliensis were more tolerant to glyphosate than the other species studied. Based on the data obtained, it can be concluded that the weeds showed differences in the foliar characteristics, with $\mathbf{C}$. benghalensis and $\boldsymbol{R}$. brasiliensis being tolerant to the highest dose of glyphosate.

Key words: tolerance, leaf anatomy, epicuticular waxes and absorption.

\section{INTRODUÇÃO}

Os herbicidas inibidores da enzima enol-piruvil shiquimato fosfato sintase (EPSPs) têm como ingrediente ativo o herbicida $\mathrm{N}$-(fosfonometil) glicina (glyphosate). Os inibidores da EPSPs perfazem 14\% das vendas globais de herbicida, sendo distribuídos em 119 países, somando mais de 150 marcas comerciais. No Brasil, esses herbicidas foram introduzidos no final da década de 1970, o que representou um impulso para o desenvolvimento do plantio direto, já que controlam grande quantidade de espécies de plantas daninhas anuais e perenes, mesmo em estado avançado de desenvolvimento (Kruse et al., 2000).

Quando se utilizam sucessivamente os mesmos herbicidas ou herbicidas diferentes, mas com mesmo mecanismo de ação, podemse selecionar biótipos resistentes ou espécies que apresentem tolerância ao produto utilizado. A tolerância é resultado da capacidade inata da espécie em suportar aplicações de herbicidas, nas doses recomendadas, sem alterações marcantes em seu crescimento e desenvolvimento. A tolerância leva à seleção natural das plantas daninhas sobre as quais o produto tiver efeito reduzido. A suscetibilidade, também, é uma característica inata de uma espécie. Nesse caso, há alterações com efeitos marcantes no crescimento e desenvolvimento da planta, como resultado de sua incapacidade de suportar a ação do herbicida (Christoffoleti et al., 2000). O glyphosate é um herbicida nãoseletivo, entretanto, nos últimos anos várias espécies de plantas daninhas têm sido relatadas como tolerantes às doses recomendadas, como Ambrosia artemisiifolia (Kapusta et al., 1994), Sesbania exaltatta e Ipomoea spp. (Jordan et al., 1997; Lich et al., 1997), entre outras. Entre os mecanismos de tolerância comprovados estão a absorção e translocação diferencial de glyphosate (Wyrill \& Burnside, 1976; D'Anieri et al., 1990); em algumas espécies pode ocorrer o metabolismo diferencial deste herbicida (Komoba et al., 1992). No Brasil, a tolerância ao glyphosate tem sido detectada em algumas espécies de plantas daninhas, como Commelina benghalensis, Commelina diffusa (Durigan et al., 1988; Santos et al., 2001), Ipomoea grandifolia e Richardia brasiliensis (Monquero, 2003).

A natureza física e química das superfícies foliares é de fundamental importância para a eficácia de herbicidas de aplicação foliar, como o glyphosate. A retenção das gotas herbicidas, por exemplo, é melhor em plantas que apresentam folhas com superficie cuticular plana, sem a presença de grandes quantidades de cristais de cera, que podem evitar que as gotas entrem diretamente em contato com a membrana cuticular. As ceras epicuticulares constituem o primeiro componente básico da membrana cuticular, podendo ser amorfas ou apresentar variáveis formas fisicas (camadas planas ou cristais de diferentes formas e tamanhos). A composição química das ceras epicuticulares é variável entre os distintos grupos filogenéticos, ocorrendo diferenças, também, dentro dos mesmos grupos, espécies ou nos diferentes estádios de desenvolvimento de um mesmo indivíduo. Os principais componentes quimicos das ceras epicuticulares são os n-alcanos, ésteres, álcoois e ácidos graxos. A importância da constituição química das ceras está relacionada com a morfologia destas. Os hidrocarbonos e álcoois primários, por exemplo, cristalizam na forma de placas; os álcoois secundários e as cetonas, como túbulos; os aldeídos, na forma de grânulos; e os dioles, como pequenas tiras (Chachalis et al., 2001).

Mendonça (2000), estudando algumas características da superfície foliar de espécies de plantas daninhas, observou que C. benghalensis apresentou ceras epicuticulares com maior porcentagem de compostos apolares, o que pode prejudicar a absorção de 
herbicidas com baixo Kow e, portanto, hidrofilicos, como é o caso do glyphosate. De acordo com Silva et al. (2000), os herbicidas lipofilicos se solubilizam nos componentes lipofilicos da cutícula e se difundem através desta. Com relação aos herbicidas hidrofilicos, admite-se que a cutícula tenha uma estrutura porosa, que se mantém hidratada, dependendo das condições ambientais, sendo essa água de hidratação da cutícula a rota de penetração hidrofilica.

O objetivo desta pesquisa foi comparar G. parviflora, C. benghalensis, I. hederifolia e $R$. brasiliensis em relação a: porcentagem de controle pelo glyphosate aplicado em diferentes doses; e características da superfície foliar, incluindo a quantificação das ceras epicuticulares.

\section{MATERIAL E MÉTODOS}

\section{Eficácia do glyphosate sobre as plantas daninhas estudadas}

O experimento foi conduzido em casa de vegetação do Departamento de Horticultura da Escola Superior de Agricultura Luiz de Queiroz, USP, Piracicaba - SP, Brasil, em copos plásticos com capacidade de $300 \mathrm{~mL}$, preenchidos com uma mistura de terra e matéria orgânica (3:1), para a semeadura das plantas daninhas Galinsoga parviflora (espécie suscetivel ao glyphosate), Ipomoea hederifolia, Richardia brasiliensis e Commelina benghalensis (espécies tolerantes ao glyphosate). Após a emergência, as plântulas foram desbastadas, para obtenção de cinco plantas por vaso. O delineamento experimental utilizado foi o inteiramente casualizado, constituído de sete tratamentos com glyphosate-Roundup ${ }^{\circledR}(0$, 360, 540, 720, 900, 1.440 e 2.160 g e.a. ha-1) e quatro repetições. Para a aplicação do herbicida, feita em pós-emergência tardia, quando as plantas daninhas estavam em pré-florescimento, utilizou-se uma câmara de aplicação experimental de herbicidas para vasos, acionada por um motor elétrico, com uma ponta de pulverização montada em bico leque modelo TeeJet $8003 \mathrm{E}$, pulverizando em média a $50 \mathrm{~cm}$ da superficie do alvo, com volume de calda de $200 \mathrm{~L}$ ha. As plantas daninhas foram avaliadas visualmente quanto à toxicidade aos 14, $21 \mathrm{e}$ 28 dias após a aplicação dos tratamentos (DAA), utilizando a escala da Asociación Latinoamericana de Malezas - ALAM (1974), em que $0 \%$ representa efeito nulo dos herbicidas sobre as plantas e $100 \%$, morte total das plantas. Os resultados referentes à porcentagem de controle foram submetidos à análise de variância, e as interações significativas tiveram suas médias comparadas pelo teste de Tukey $(\mathrm{P}<0,05)$.

\section{Caracterização da superficie foliar das plantas daninhas}

As ceras epicuticulares foram extraídas de 20 plantas de C. benghalensis, I. hederifolia e $R$. brasiliensis e G. parviflora cultivadas em casa de vegetação do Departamento de Horticultura da Escola Superior de Agricultura Luiz de Queiroz, USP, Piracicaba-SP, Brasil. As análises foram feitas quando as plantas daninhas apresentavam quatro folhas totalmente expandidas. As folhas de cada espécie de planta daninha foram introduzidas separadamente em placas com clorofórmio e metanol $(90: 10 \mathrm{~mL})$ por 30 segundos, agitandose levemente. Esses procedimentos foram feitos cuidadosamente, para evitar a ruptura das folhas e a conseqüente liberação de clorofila e outros compostos. Os extratos obtidos foram filtrados e deixados evaporar sobre uma placa a $55^{\circ} \mathrm{C}$, até reduzir o volume para aproximadamente $15 \mathrm{~mL}$. Esta solução (clorofórmio +ceras) foi transferida para recipientes de $25 \mathrm{~mL}$ de peso conhecido. O clorofórmio foi evaporado em temperatura ambiente e os recipientes foram mantidos para pesagem dois e quatro dias após a obtenção do resíduo sólido

Tabela 1 - Análise química do substrato utilizado para semeadura das plantas daninhas

\begin{tabular}{|c|c|c|c|c|c|c|c|c|c|c|}
\hline \multirow{2}{*}{$\mathrm{pH} \mathrm{CaCl}{ }_{2}$} & M.O & $\mathrm{P}$ & S-SO & $\mathrm{K}$ & $\mathrm{Ca}$ & $\mathrm{Mg}$ & $\mathrm{Al}$ & $\mathrm{SB}$ & $\mathrm{T}$ & V\% \\
\hline & $\left(\mathrm{g} \mathrm{dm}^{-3}\right)$ & \multicolumn{2}{|c|}{$\left(\mathrm{mg} \mathrm{dm}^{-3}\right)$} & \multicolumn{4}{|c|}{$\left(\mathrm{mmol}_{\mathrm{c}} \mathrm{dm}^{-3}\right)$} & & & \\
\hline 6,4 & 47 & 468 & 127 & 15,2 & 111 & 29 & 0 & 155,2 & 170,2 & 91 \\
\hline
\end{tabular}


(ceras). A quantificação das ceras foi expressa por quantidade de ceras por unidade de área foliar $\left(\mu \mathrm{g} \mathrm{cm}^{-2}\right)$. Para isso, a área das folhas de cada espécie, utilizadas para a extração das ceras, foi medida através do aparelho fotoelétrico de medição de área foliar da marca LICOR-3100. O experimento foi conduzido em delineamento inteiramente casualizado, com quatro repetições para cada espécie. Foram calculadas as médias das quatro repetições, juntamente com os respectivos desvios-padrão.

Dois segmentos de aproximadamente $50 \mathrm{~mm}^{2}$ foram retirados da região mediana das folhas jovens, porém totalmente expandidas, das referidas espécies, para análise das superfícies adaxial e abaxial em microscópio eletrônico de varredura.

Os segmentos vegetais foram fixados em temperatura ambiente por uma hora, utilizando-se fixador Karnovsky modificado (glutaraldeído $2,5 \%$, formaldeído $2,5 \%$ em tampão cacodilato de sódio 0,05 M, pH 7,2). Em seguida, as amostras foram lavadas em solução-tampão de cacodilato $0,1 \mathrm{M}$, com três passagens de cerca de 20 minutos cada. Após esse processo, o material foi lavado três vezes com água destilada, seguindo, então, para a desidratação em soluções crescentes de acetona $(35,50,60$, $75,85,95$ e $100 \%$ ), permanecendo cerca de 20 minutos em cada uma; na solução de $100 \%$ ele foi passado três vezes por 20 minutos.
Após a desidratação, as amostras foram colocadas para secagem ao ponto crítico em uma câmara hermeticamente fechada que permite a entrada de $\mathrm{CO}_{2}$, que se liquefaz, ficando a amostra nele mergulhada. Esta câmara é aquecida até $40{ }^{\circ} \mathrm{C}$, quando então o gás é lentamente eliminado e as amostras ficam secas, sem terem sofrido problemas de tensão superficial.

As amostras secas foram então montadas em stubs, recobertas com uma fina camada de ouro com espessura de 0,05 $\mu \mathrm{m}$, para se evitar a reidratação (Bozzola \& Russel, 1992), e levadas para observação em microscópio eletrônico de varredura Zeiss, modelo DSM 940A, sendo fotografadas as melhores imagens.

\section{RESULTADOS E DISCUSSÃO}

\section{Eficácia do glyphosate sobre as plantas daninhas estudadas}

De acordo com a Tabela 2, pode-se observar que a planta daninha I. hederifolia não foi controlada satisfatoriamente pelas menores doses do glyphosate, havendo recuperação da toxicidade aos 28 DAA. Esta planta daninha foi controlada de maneira eficiente apenas com a dose de 2.160 g e.a. ha ${ }^{-1}$, que proporcionou controle de $85 \%$. Em C. benghalensis, os tratamentos com glyphosate 360 e 540 g e.a. ha ${ }^{-1}$ ocasionaram uma leve toxicidade aos 28 DAA

Tabela 2 - Controle de I. hederifolia, C. benghalensis, R. brasiliensis e G. parviflora aos 14, 21 e 28 dias após aplicação dos tratamentos (DAA)

\begin{tabular}{|c|c|c|c|c|c|c|c|c|c|c|c|c|}
\hline \multicolumn{13}{|c|}{$\%$ CONTROLE } \\
\hline & \multicolumn{3}{|c|}{$\mathrm{IPOHF}^{1 /}$} & \multicolumn{3}{|c|}{$\mathrm{COMBE}^{2 /}$} & \multicolumn{3}{|c|}{$\mathrm{RCHBR}^{3 /}$} & \multicolumn{3}{|c|}{$\mathrm{GASPA}^{4 /}$} \\
\hline $\begin{array}{l}\text { Glyphosate } \\
\left(\text { g e.a.ha }^{-1}\right)\end{array}$ & 14 & 21 & 28 & 14 & 21 & 28 & 14 & 21 & 28 & 14 & 21 & 28 \\
\hline 360 & $17,50 \mathrm{~d}$ & $16,25 \mathrm{~d}$ & $11,25 \mathrm{f}$ & $12,50 \mathrm{e}$ & $12,50 \mathrm{e}$ & $10,00 \mathrm{~g}$ & $6,10 \mathrm{~cd}$ & $11,26 \mathrm{~b}$ & $14,82 \mathrm{bc}$ & $71,53 \mathrm{ab}$ & $81,30 \mathrm{a}$ & $90,30 \mathrm{a}$ \\
\hline 540 & $18,75 \mathrm{~d}$ & $25,00 \mathrm{~cd}$ & $18,75 \mathrm{e}$ & $20,00 \mathrm{de}$ & $20,01 d$ & $18,75 \mathrm{f}$ & $16,76 \mathrm{bcd}$ & $19,88 \mathrm{ab}$ & $23,50 a b c$ & $85,80 \mathrm{ab}$ & $96,31 \mathrm{a}$ & $98,73 a$ \\
\hline 720 & $30,25 \mathrm{c}$ & $32,50 \mathrm{bc}$ & $38,75 \mathrm{~d}$ & $25,00 \mathrm{~cd}$ & $40,00 \mathrm{c}$ & $38,75 \mathrm{~d}$ & $39,97 \mathrm{abc}$ & $38,71 \mathrm{ab}$ & $42,49 \mathrm{ab}$ & $93,00 \mathrm{ab}$ & $100,00 \mathrm{a}$ & $100,00 \mathrm{a}$ \\
\hline 900 & $32,50 \mathrm{c}$ & $40,00 \mathrm{~b}$ & $50,00 \mathrm{c}$ & $33,75 b c$ & $42,50 \mathrm{c}$ & $58,75 \mathrm{c}$ & $58,78 \mathrm{abc}$ & $58,70 \mathrm{a}$ & $51,25 \mathrm{ab}$ & $100,00 \mathrm{a}$ & $100,00 \mathrm{a}$ & $100,00 \mathrm{a}$ \\
\hline 1.440 & $55,00 \mathrm{~b}$ & $70,00 \mathrm{a}$ & $70,00 \mathrm{~b}$ & $41,25 \mathrm{a}$ & $60,00 \mathrm{~b}$ & $71,25 b$ & $70,06 \mathrm{ab}$ & $67,52 \mathrm{a}$ & $71,27 \mathrm{ab}$ & $100,00 \mathrm{a}$ & $100,00 \mathrm{a}$ & $100,00 \mathrm{a}$ \\
\hline 2.160 & $67,50 \mathrm{a}$ & $71,25 a$ & $85,00 \mathrm{a}$ & $57,50 \mathrm{a}$ & $75,00 \mathrm{a}$ & $80,00 a$ & $78,78 a$ & $77,54 a$ & $77,54 a$ & $100,00 \mathrm{a}$ & $100,00 \mathrm{a}$ & $100,00 \mathrm{a}$ \\
\hline 0 & $0,00 \mathrm{e}$ & $0,00 \mathrm{e}$ & $0,00 \mathrm{~g}$ & $0,00 \mathrm{f}$ & $0,00 \mathrm{f}$ & $0,00 \mathrm{~h}$ & $0,00 \mathrm{~d}$ & $0,00 \mathrm{~b}$ & $0,00 \mathrm{c}$ & $0,00 \mathrm{~b}$ & $0,00 \mathrm{~b}$ & $0,00 \mathrm{~b}$ \\
\hline $\mathrm{CV} \%$ & 14,583 & 13,813 & 6,455 & 16,827 & 7,902 & 6,601 & 62,16 & 66,55 & 55,03 & 52,67 & 54,11 & 54,19 \\
\hline DMS 5\% & 10,56 & 11,28 & 6,17 & 9,52 & 6,48 & 6,68 & 38,02 & 39,27 & 35,05 & 45,23 & 43,44 & 42,45 \\
\hline
\end{tabular}

${ }^{1 /}$ I. hederifolia ${ }^{2 /}$ C. benghalensis; ${ }^{3 /}$ R. brasiliensis, ${ }^{4 /}$ G. parviflora. 
(10 a $18 \%$ de controle); nas doses de 1.440 e $2.160 \mathrm{~g}$ e.a. $\mathrm{ha}^{-1}$ o controle foi apenas aceitável: na faixa de 71 a $85 \%$ (Tabela 2). Esta planta daninha se reproduz por sementes aéreas, sementes subterrâneas e fragmentos de caule; portanto, mesmo que o controle seja efetivo, a capacidade de reinfestação é muito grande.

Diversas pesquisas vêm sendo conduzidas com o objetivo de avaliar a eficiência das aplicações de glyphosate em mistura com herbicidas que apresentem diferentes mecanismos de ação no controle de plantas tolerantes. Nessa linha de pesquisa, Santos et al. (2002a) observaram que em $C$. benghalensis o herbicida 2,4-D proporcionou controle excelente (>91\%) aos 33 dias após tratamento a partir de 167,5 g i.a. ha ${ }^{-1}$ na presença de glyphosate e, a partir de 335 g i.a. ha ${ }^{-1}$, na ausência deste herbicida. Segundo Rochi et al. (2002), os tratamentos mais eficientes no controle de trapoeraba foram as aplicações seqüenciais, com intervalo de 21 dias, de (paraquat + diuron)/(carfentrazone-ethyl + glyphosate) e de (paraquat + diuron)/(paraquat + diuron). Lacerda (2003) observou que o herbicida glyphosate apresentou controle acima de 90\% com a dose de 720 g e.a. ha ${ }^{-1}$ para Bidens pilosa e Digitaria insularis, 960 g e.a. ha ${ }^{-1}$ para Tridax procumbens, $1.440 \mathrm{~g}$ e.a. ha $\mathrm{ha}^{-1}$ para Ipomoea grandifolia e $1.680 \mathrm{~g}$ e.a. ha $\mathrm{ha}^{-1}$ para Commelina benghalensis.

No caso de $R$. brasiliensis, mesmo as maiores doses do glyphosate não controlaram de maneira eficaz esta planta daninha quando adulta (Tabela 2). O controle permaneceu menor que $80 \%$ aos 28 DAA. De acordo com Rodrigues \& Almeida (1995), R. brasiliensis é uma espécie mediamente suscetivel a este herbicida em pós-emergência tardia. Kozlowski (2001) verificou que os herbicidas sulfosate (878 g e.a. ha ${ }^{-1}$ ) e glyphosate CS (960 g e.a. ha-1), em sistema de plantio direto, foram os melhores tratamentos para o controle de $R$. brasiliensis.

Em G. parviflora, todas as doses de glyphosate proporcionaram ótimo controle, chegando a $100 \%$ a partir de 720 g e.a. ha ${ }^{-1}$ (Tabela 2). O controle satisfatório desta planta é importante, pois é uma espécie que pode desenvolver várias gerações por ano (Kissmann \& Groth, 1992).
Monquero (2003) estudou a dinâmica do banco de sementes das plantas daninhas G. parviflora, R. brasiliensis, C. benghalensis, I. grandifolia e A. hybridus, em áreas com aplicações repetitivas do herbicida glyphosate. Os resultados indicam que o glyphosate reduz o número de sementes ao longo do tempo; entretanto, sua aplicação repetitiva pode modificar a composição específica de plantas daninhas da área, levando à predominância de espécies tolerantes ao glyphosate, como C. benghalensis, I. grandifolia e R. brasiliensis. Assim, é importante o monitoramento das infestações de plantas daninhas nas áreas onde o glyphosate é utilizado repetitivamente no manejo de plantas daninhas, a fim de que medidas sejam adotadas no sentido de evitar a predominância de espécies tolerantes.

\section{Caracterização da superficie foliar das plantas daninhas}

A quantidade de ceras por unidade de área foliar foi maior em $I$. hederifolia $\left(38,5 \mu \mathrm{g} \mathrm{cm}^{-2}\right)$, seguida por $C$. benghalensis $\left(34,5 \mu \mathrm{g} \mathrm{cm}^{-2}\right)$, G. parviflora $\left(31,7 \mu \mathrm{g} \mathrm{cm}^{-2}\right)$ e $R$. brasiliensis $\left(23,4 \mu \mathrm{g} \mathrm{cm}^{-2}\right)$. Na maioria das espécies esses valores variam de 10 a $200 \mu \mathrm{g} \mathrm{cm}^{-2}$ (McWhorter, 1993), embora quantidades acima de $300 \mu \mathrm{g} \mathrm{cm}^{-2}$ já tenham sido relatadas (Baker, 1982). A retenção de herbicidas sobre a superficie foliar das plantas é afetada pela cerosidade, pela estrutura fisica característica da cutícula e pela pilosidade. Plantas que possuam grandes quantidades de ceras epicuticulares sobre a superficie adaxial das folhas podem apresentar menor retenção das gotas herbicídicas, e, portanto, menor absorção. A maioria dos estresses ambientais pode induzir mudanças na composição e na estrutura da membrana cuticular, as quais podem influenciar a absorção de herbicidas. Aumento da temperatura e baixa umidade relativa do ar tendem a induzir a sintese de ceras epicuticulares, com conseqüente aumento do caráter lipofílico da superficie foliar (Oliveira \& Bacarin, 2001).

$\mathrm{Na}$ Figura 1A, observa-se uma vista geral da superfície adaxial da folha de C. benghalensis, mostrando que há dois tipos de tricomas: uma grande quantidade de

Planta Daninha, Viçosa-MG, v. 23, n. 1, p. 123-132, 2005 
tricomas tectores multicelulares e tricomas menores, em forma de gancho. Santos et al. (2002b), avaliando as diferenças entre os caracteres anatômicos de $C$. benghalensis e C. diffusa, observaram que o complexo estomático das duas espécies é semelhante e a folha é anfiestomática; o número de estômatos na epiderme foliar foi maior em C. diffusa; já C. benghalensis apresentou dois tipos de pêlos tectores: longos com a extremidade afilada e curtos com a extremidade curva - os pêlos longos concentram-se na epiderme abaxial e os pêlos curtos, na epiderme adaxial. Na Figura 1B, observa-se a superficie adaxial de $C$. benghalensis, com ceras epicuticulares cristalizadas na forma de grânulos, e detalhe dos estômatos, que são dispersos de forma aleatória. Os estômatos desta espécie de planta daninha são classificados como tetracíticos, por serem envolvidos por quatro células subsidiárias, duas delas paralelas às células-guarda, sendo o par restante polar e freqüentemente menor (Da Glória \& Guerreiro, 2003). Na Figura 1C-D observa-se a superficie abaxial, que apresenta tricomas e estômatos, mas sem a presença dos grânulos de ceras. De acordo com Mendonça (2000), os estômatos de $C$. benghalensis tiveram forma arredondada e estavam dispersos ao acaso na superfície foliar; além disso, a superfície adaxial apresentou escassas quantidades de ceras epicuticulares. Segundo esta mesma autora, $C$. benghalensis apresenta grande porcentagem de compostos apolares nas ceras epicuticulares. O herbicida glyphosate possui baixo Kow, apresentando pouca afinidade a lipídios; portanto, ceras epicuticulares com grande quantidade de compostos apolares podem representar uma barreira à penetração deste herbicida.
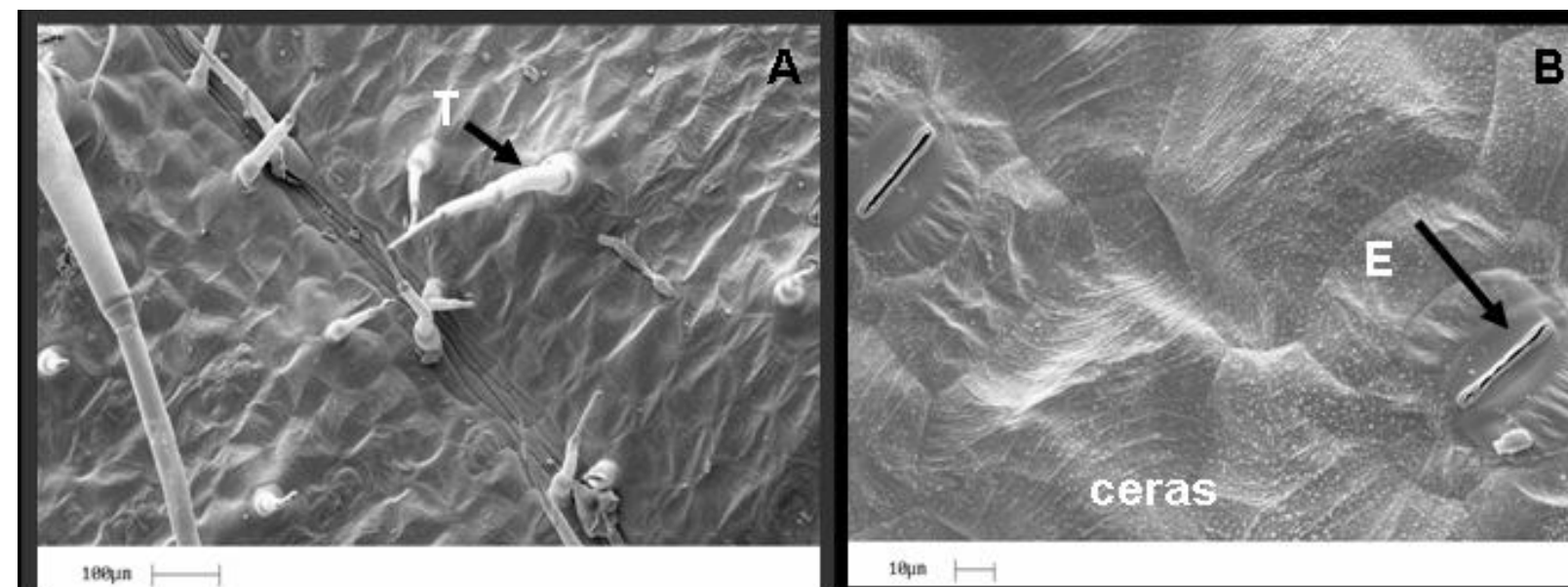

18) $\longmapsto$

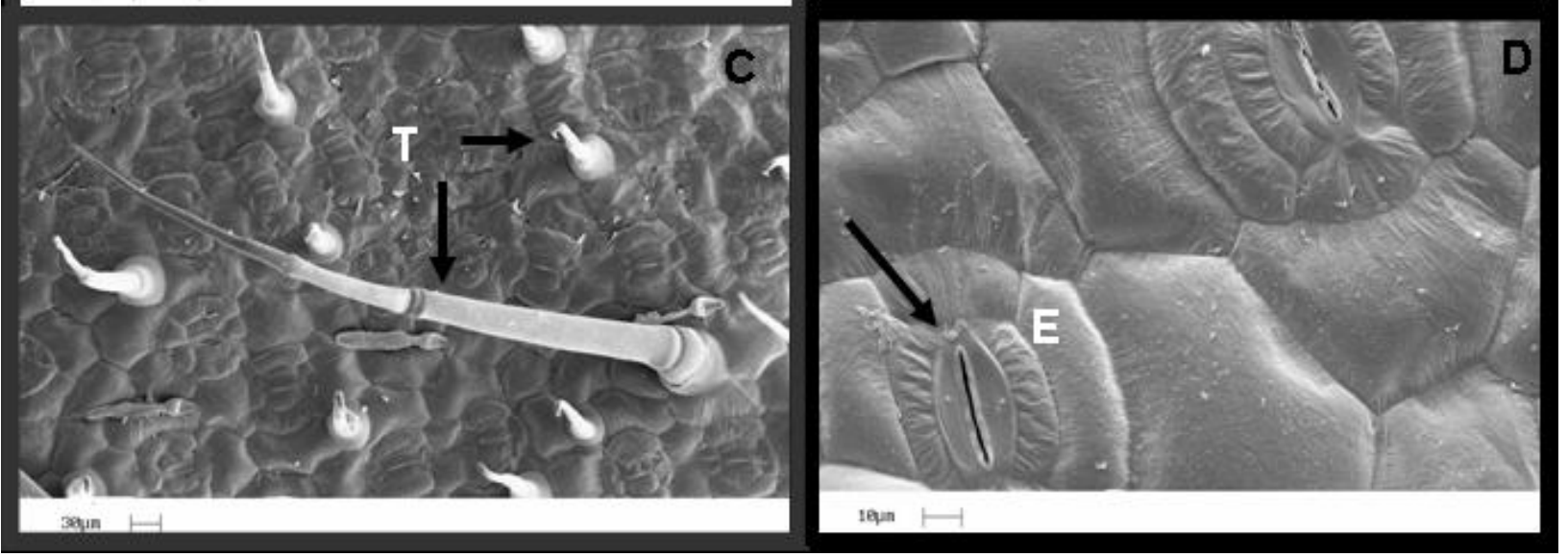

Figura 1 - Análise da superfície adaxial (A-B) da folha de C. benghalensis, com detalhes dos tricomas (T), estômatos (E) e grânulos de ceras epicuticulares sobre toda a superfície; na superfície abaxial (C-D), tricomas e estômatos. 
Na Figura 2 A-B, observa-se na superficie adaxial de $R$. brasiliensis a presença de tricomas tectores unicelulares elongados e estômatos paracíticos, ou seja, estômatos envolvidos por duas células subsidiárias, cujos eixos longitudinais são paralelos ao das células-guarda. Não foi notada a presença de depósitos de ceras epicuticulares. A superficie abaxial (Figura $2 \mathrm{C}$-D) é semelhante à adaxial, porém com menor número de tricomas.

Na Figura 3 A-B, a superficie adaxial de I. hederifolia se mostra totalmente enrugada e com a presença de dois tipos de tricomas: os tricomas tectores unicelulares e tricomas glandulares. No caso do tricoma glandular, a extremidade é formada por uma cabeça unicelular, que se une à epiderme por meio de uma haste tão curta que parece um disco; além disso, as células que constituem a cabeça são secretoras e normalmente contêm numerosas mitocôndrias e outras organelas, que variam de acordo com o material secretado (Da Gloria \& Guerreiro, 2003). Podem-se observar também detalhes dos estômatos paracíticos que se encontram em grande quantidade na superficie foliar, tanto na face adaxial quanto na abaxial (Figura $3 \mathrm{C}$-D). Não foi detectada a presença de cristais de ceras epicuticulares em ambas as faces da superficie foliar. A ausência de cristais de ceras epicuticulares também foi observada em outras espécies de plantas, como Vitis vinifera, Beta vulgares e Trifolium repens. A presença de ceras amorfas pode estar associada à baixa quantidade de ceras na superficie foliar ou à predominância de álcool primário na composição química das ceras (Baker \& Bukovac, 1971). De acordo com Monquero (2003), a superficie adaxial de I. grandifolia se apresentou rugosa, porém sem a presença de tricomas e de cristais de ceras.
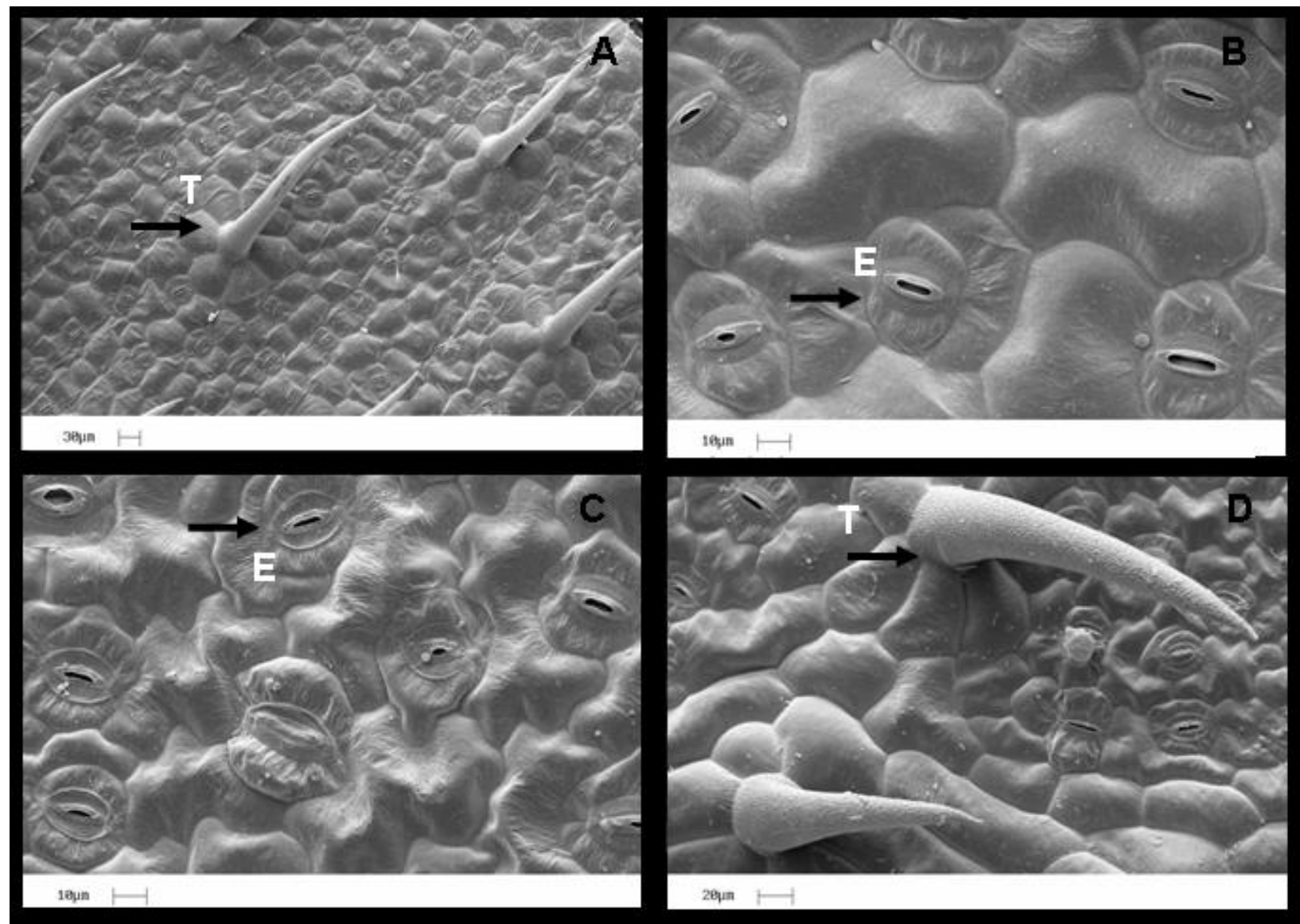

Figura 2 - Análise das superfícies adaxial (A-B) e abaxial (C-D) da folha de $R$. brasiliensis, com detalhes dos tricomas (T) e estômatos (E). 


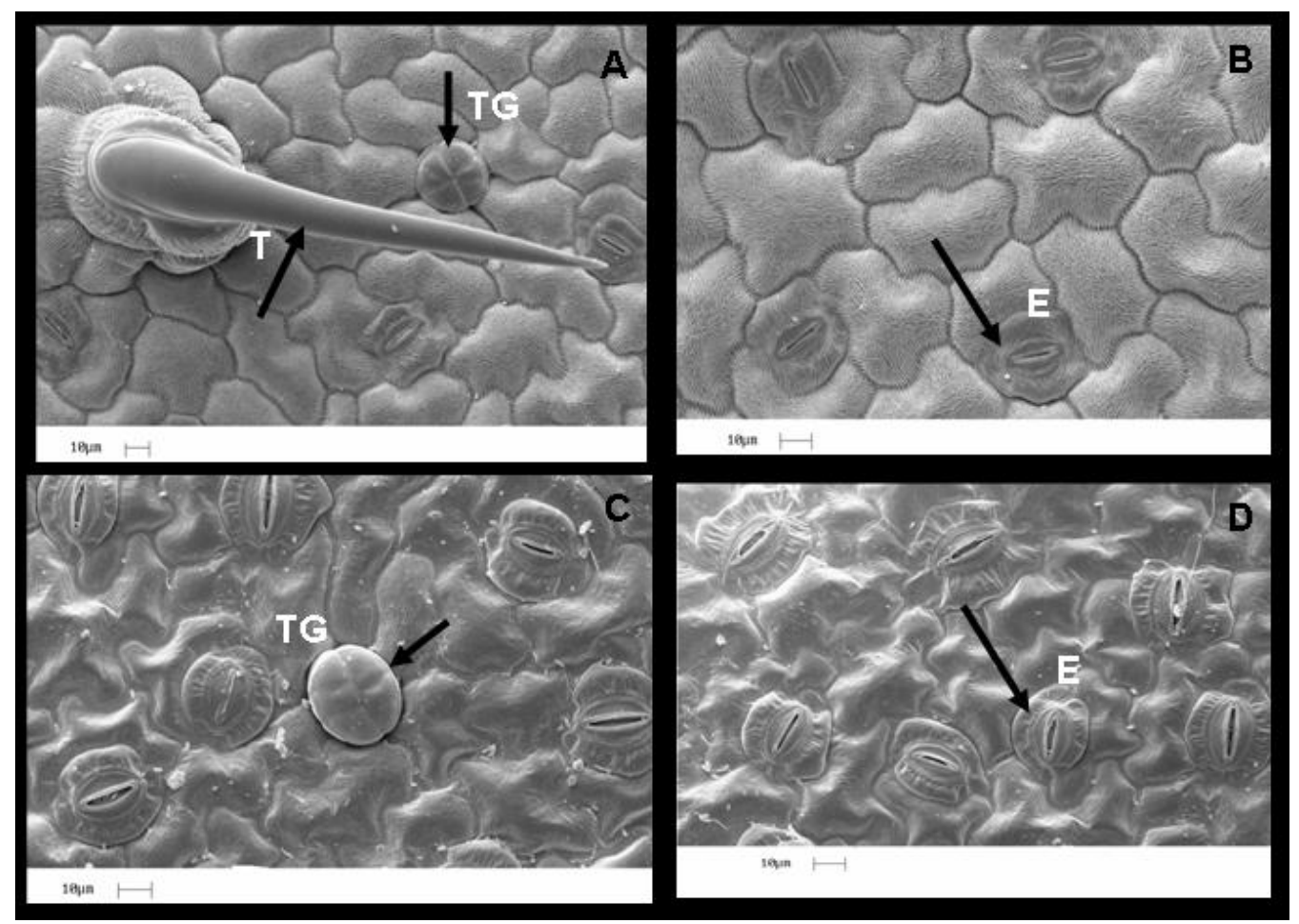

Figura 3 - Análise da superfície adaxial (A-B) da folha de I. hederifolia, com detalhes de superfície rugosa, tricomas (T), tricomas glandulares (TG) e estômatos (E); abaixo, estômatos e glândulas sobre a superfície abaxial (C e D).

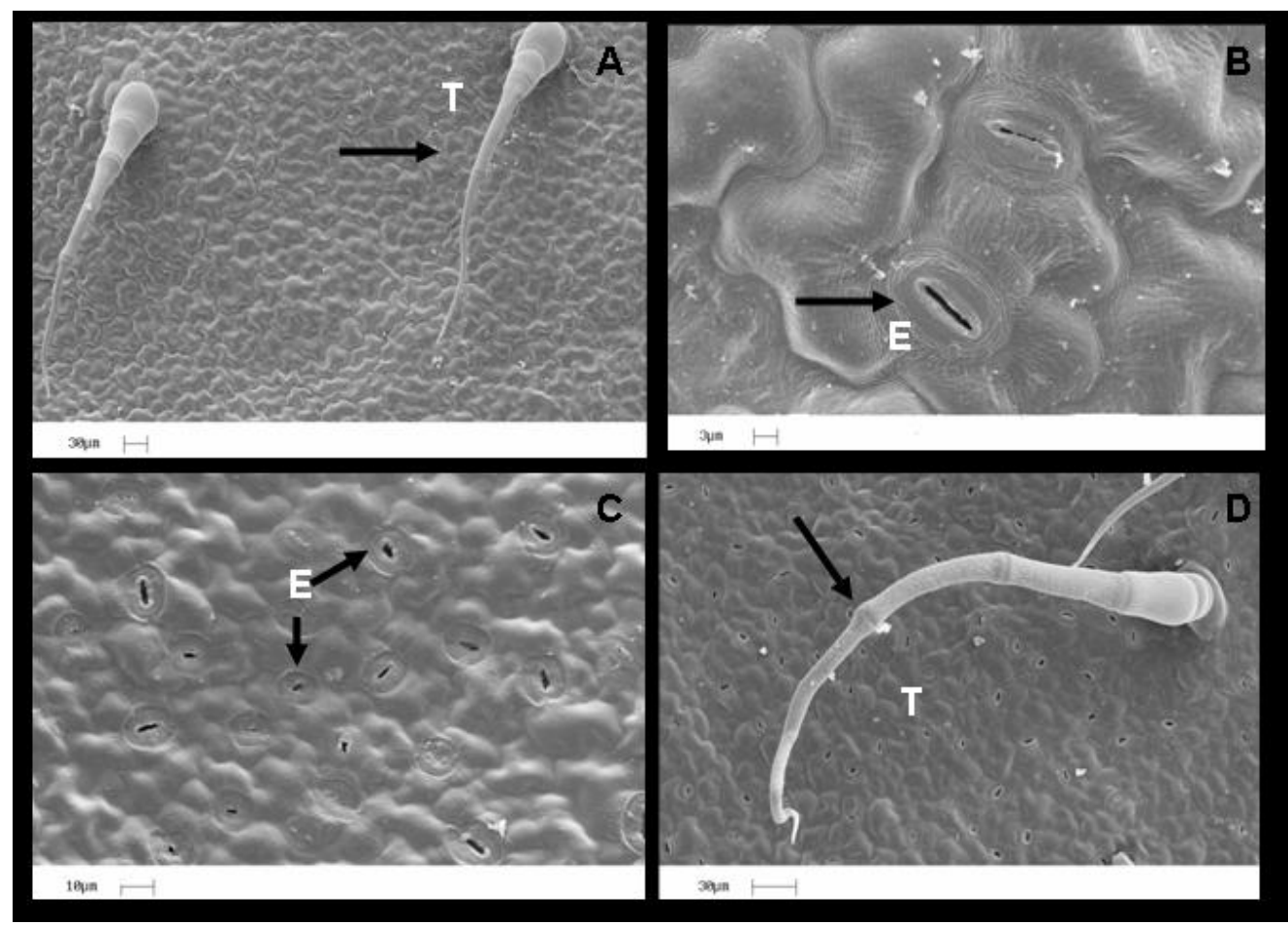

Figura 4 - Análise das superfícies adaxial (A-B) e abaxial (C-D) da folha de G. parviflora, com detalhes dos tricomas (T) e estômatos (E). 
A planta daninha G. parviflora apresenta, sobre as superficies adaxial (Figura 4 A-B) e abaxial (Figura $4 \mathrm{C}$-D), tricomas tectores multicelulares não-ramificados e estômatos anomocíticos, ou seja, que não apresentam células subsidiárias diferenciadas. Procópio et al. (2003) observaram que a principal barreira foliar à penetração de herbicidas em G. parviflora é a baixa densidade estomática sobre a superfície adaxial. É importante lembrar que a membrana cuticular sobre as células-guarda se apresenta mais fina e permeável, facilitando a entrada de água e soluções.

\section{LITERATURA CITADA}

ASOCIACIÓN LATINOAMERICANA DE MALEZASALAM. Recomendaciones sobre a unificación de los sistemas de evaluación en ensayos de control de malezas. ALAM, v. 1, p. 35-38, 1974.

BAKER, E. A. Chemistry and morphology of plant epicuticular waxes. In: CUTLER, D. F.; ALVIN, K. L.; PRICE, C. E. (Eds.) The plant cuticle. London: Academic Press, 1982. p. 140-161.

BAKER, E. A.; BUKOVAC, M. J. Characterization of the components of plant cuticles in relation to the penetration of 2,4-D. An. Appl. Biol., v. 67, p. 243-253, 1971.

BOZZOLA, J. J.; RUSSEL. L. D. Electron microscopy. Boston: Jones and Bartlett Publishers, 1992. 542 p.

CHACHALIS, D. et al. Characterization of leaf surface, wax composition, and control of redvine and trumpetcreeper with glyphosate. Weed Sci., v. 49, p. 156-163, 2001.

CHRISTOFFOLETI, P. J. et al. Plantas daninhas na cultura da soja: controle químico e resistência a herbicidas. In: CÂMARA, G. M. (Ed.) Soja: tecnologia da produção. Piracicaba: ESALQ, 2000. p. 179-202.

DA GLORIA, B. A.; GUERREIRO, C. S. M. Anatomia vegetal. Viçosa: Universidade Federal de Viçosa, 2003. $438 \mathrm{p}$.

D'ANIERI, P. et al. Glyphosate translocation and efficacy relationships in red maple, sweetgum and loblolly penne seedlings. For. Sci., v. 36, p. 438-447, 1990.

DURIGAN, J. C.; GALLI, A. J. B.; LEITE, G. J. Avaliação da eficiência da mistura de glyphosate e 2,4-D para o controle de plantas daninhas em citros. In: CONGRESSO BRASILEIRO DE HERBICIDAS E PLANTAS DANINHAS, 17., 1988, Piracicaba. Resumos... Piracicaba: SBEHD, 1988. p. 303-304.
JORDAN, D. L. et al. Influence of application variables on efficacy of glyphosate. Weed Technol., v. 11, p. 354-362, 1997.

KAPUSTA, G.; KRAUZ, R. F.; MATTHEWS, J. L. Soybean tolerance and summer annual weed control with glufosinate and glyphosate in resistant soybean. Weed Sci. Soc., v. 49, p. 120-124, 1994.

KISSMANN, K. G.; GROTH, D. Plantas infestantes e nocivas. São Paulo: BASF Brasileira, 1992. v. 2. 798 p.

KOMOBA, D.; GENNITY, I.; SANDERMANN, H. Plant metabolism of herbicides with C-P bonds glyphosate.

Pestic. Biochem. Physiol., v. 43, p. 85-94, 1992.

KOZLOWSKI, L. A. Eficácia de herbicidas de manejo no controle de Richardia brasiliensis em semeadura direta na cultura do feijoeiro. R. Bras. Herb., v. 2, n. 3, p. 149-153, 2001.

KRUSE, N. D.; TRESSI, M. M.; VIDAL, R. A. Herbicidas inibidores da EPSPs: revisão de literatura. R. Bras.

Herbicidas, n. 1, v. 2, p. 139-146, 2000.

LACERDA, A. Fluxo de emergência e banco de sementes de plantas daninhas em sistemas de semeadura direta e convencional e curva de doseresposta ao glyphosate. 2003. $117 \mathrm{f}$. Tese (Doutorado em Fitotecnia) - Escola Superior de Agricultura "Luiz de Queiroz", Piracicaba, 2003.

LICH, J. M.; RENNER, K. A.; PENNER, D. Interaction of glyphosate with postemergence soybeans (Glycine max) herbicides. Weed Sci., v. 45, p. 12-21, 1997.

MCWHORTER, C. G.; OUZTS, C. Leaf surface morphology of Erythroxylum sp and droplet spread. Weed Sci., v. 42, p. 18-26, 1993.

MENDONÇA, G. G. Algumas características da superfície foliar de diversas plantas daninhas monocotiledôneas. 2000. 89 f. Dissertação (Mestrado em Produção Vegetal) - Universidade Estadual Paulista, Botucatu, 2000.

OLIVEIRA, R. S.; BACARIN, M. A. Banco de sementes e mecanismos de dormência em sementes de plantas daninhas. In: OLIVEIRA, R. S.; CONSTATIN, J. (Eds.). Plantas daninhas e seu manejo. Guaíba: Agropecuária, 2001. p. 261-290.

MONQUERO, P. A. Dinâmica populacional e mecanismos de tolerância de espécies de plantas daninhas ao herbicida glyphosate. 2003. 99 f. Tese (Doutorado em Fitotecnia) - Escola Superior de Agricultura “Luiz de Queiroz", Piracicaba, 2003.

Planta Daninha, Viçosa-MG, v. 23, n. 1, p. 123-132, 2005 
PROCÓPIO, S. O. et al. Estudos anatômicos de folhas de espécies de plantas daninhas de grande ocorrência no Brasil III-Galinsoga parviflora, Crotalaria incana, Conyza bonariensis e Ipomoea cairica. Planta Daninha, v. 21, p. 1-9, 2003.

ROCHI, C. P. et al. Misturas de herbicidas para o controle de plantas daninhas do gênero Commelina. Planta

Daninha, v. 20, p. 319-325, 2002.

SANTOS, I. C. et al. Eficiência de glyphosate no controle de Commelina benghalensis e Commelina diffusa. Planta Daninha, v. 19, p. 135-143, 2001.
SANTOS, I. C. et al. Eficiência de 2,4-D aplicado isoladamente e em mistura com glyphosate no controle de trapoeraba. Planta Daninha, v. 20, p. 299-318, 2002a.

SANTOS, I. C. et al. Caracteres anatômicos de duas espécies de trapoeraba e a eficiência do glyphosate. Planta Daninha, v. 20, p. 1-8, 2002 b.

SILVA, A. A. et al. Controle de plantas daninhas. Brasília: ABEAS, 2000. 260 p.

WYRILL, J. B. III; BURNSIDE, O. C. Absorption, translocation and metabolism of 2,4-D and glyphosate in common milkweed and hemp dogbane. Weed Sci., v. 24, p. 557-566, 1976. 